\title{
TRÁFICO DE CRIANÇAS E ADOLESCENTES NO BRASIL: UMA ANÁLISE DAS OCORRÊNCIAS À LUZ DA DOUTRINA DA PROTEÇÃO INTEGRAL
}

\section{Yasmim Pamponet Sá ${ }^{1}$ Andreza do Socorro Pantoja de Oliveira Smith ${ }^{2}$}

RESUMO: Estuda-se o tráfico de crianças e adolescentes no Brasil considerando-se o Relatório Nacional sobre o Tráfico de Pessoas: dados 2014 a 2016. Analisa-se as possíveis finalidades das ocorrências no país em face da lacuna nos dados publicados. Realiza-se abordagem crítica do fenômeno considerando-se os postulados da doutrina da proteção integral da criança e do adolescente, para demonstrar em que medida se concretiza a proteção integral de crianças vítimas de tráfico de pessoas no contexto da política brasileira e do III Plano Nacional de enfrentamento ao tráfico de pessoas. Para tanto, utilizou-se a pesquisa bibliográfica e documental especializada.

Palavras-chave: Tráfico de Pessoas. Crianças e Adolescentes. Proteção integral. Política Brasileira. III Plano Nacional de Enfrentramento ao Tráfico de Pessoas.

\section{HUMAN TRAFFICKING OF CHILDREN AND ADOLESCENTS IN BRAZIL: AN ANALYSIS OF OCCURRENCES IN LIGHT OF THE FULL PROTECTION DOCTRINE}

\begin{abstract}
The human trafficking of children and adolescents in Brazil is studied considering the National Report on Human Trafficking: data from 2014 to 2016. The possible purposes of the occurrences in the country are analyzed facing the gap in the published data. A critical approach of the phenomenon is carried out considering the postulates of the full protection doctrine of children and adolescents, to demonstrate to what extent the full protection of child victims of human trafficking is achieved in the context of the brazilian policy and the III National Plan to combat human trafficking. For this purpose, specialized documental and bibliografic research were used.
\end{abstract}

KEYWORDS: Human Trafficking. Children and Adolescents. Full Protection. Brazilian Policy. III National Plan to Combat Human Trafficking.

\section{INTRODUÇÃ̃O}

No presente artigo, analisa-se o fenômeno do tráfico de crianças e adolescentes no Brasil, a partir dos dados publicados em 2017 pelo Ministério da Justiça no Relatório Nacional sobre o

\footnotetext{
${ }^{1}$ Assessora Jurídica da Defensoria Pública do Estado do Pará, lotada no Núcleo de Atendimento Especializado da Criança e do Adolescente. Mestranda do Programa de Pós-graduação em Direito da Universidade Federal do Pará. R. Augusto Corrêa, s/n (Av. Perimetral), 66075-110, Belém/PA. E-mail: yasmimpamponetsa@gmail.com.

${ }^{2}$ Advogada. Doutora em Direito pela Universidade Federal do Pará. Professora da Graduação e Pós-Graduação em Direito da Universidade do Pará. R. Augusto Corrêa, s/n (Av. Perimetral), 66075-110, Belém/PA. E-mail: andrezasmith@ufpa.br.
} 
Tráfico de Pessoas: dados 2014 a 2016, um vez que este é o último documento nacional que se refere ao problema. O estudo é apoiado na doutrina da proteção integral preconizada internacionalmente e incorporada ao ordenamento jurídico brasileiro, isto é, promovendo o paradigma da peculiar condição da pessoa em desenvolvimento e elevando-a ao patamar de sujeito de direito.

De início, informa-se que neste trabalho se utiliza a definição de criança e adolescente constante da Lei 8.069, de 13 de julho de 1990, o Estatuto da Criança e do Adolescente, que em seu art. $2^{\circ}$ dispõe que a criança é a pessoa até doze anos de idade incompletos e adolescente é a pessoas de 12 a 18 anos de idade.

O objetivo ímpar deste estudo consiste em uma tentativa de fornecer avaliações iniciais a fim de se chegar a possíveis respostas satisfatórias ao problema de pesquisa posto, qual seja: em que medida é possível se falar em proteção integral de crianças e adolescentes vítimas de tráfico de pessoas no Brasil no contexto da política nacional de enfrentamento ao tráfico de pessoas?

Importate ressaltar que, apesar de o presente trabalho consistir em uma análise essencialmente jurídica, realizada a partir da pesquisa bibliográfica e documental especializada, que nesse sentido investiga a concretização de um tipo legal (tráfico de pessoas) em um contexto nacional, a complexidade do referido problema impõe a utilização de um olhar interdisciplinar.

$\mathrm{O}$ direito possui características ligadas tanto a elementos processuais quanto a pressupostos epistemológicos que tornam difícil compreender uma questão como a que ora se impõe. Isso porque o tráfico de crianças configura um crime que, de maneira mais perversa que outros, impõe duradouro sofrimento psíquico às suas vítimas, entrelaçando suas narrativas com as de agentes criminosos, família de origem, família receptora, etc.

O problema, então, reside no fato de que a redução de uma narrativa aos pontos tidos como "relevantes juridicamente" à velocidade do desenrolar processual, bem como a binariedade entre fato e ilícito que muitas vezes limita a percepção jurídica de um problema, são alguns dos elementos que apontam para a necessidade de uma abordagem mais ampla.

Ademais, válido ressaltar que o contexto latino-americano impõe uma leitura decolonial da situação jurídica e social da criança e do adolescente, o que se faz no presente trabalho conforme lições de ABRAMOVICZ e RODRIGUES:

(...) estamos entendendo o processo de descolonização no interior de uma das possibilidades de constituir-se de maneira singular, produzindo e criando novas/outras possibilidades de vida, de criança(s), de infância(s) e de pesquisa(s). (...) Descolonizar é produzir uma processualidade na qual é possível constituir experiências sociais e individuais singulares, que descentralizem, ou façam fugir os modelos e lugares 
hegemônicos que centralizam sentidos, norma, estética, saúde, entre outros, dominantes e que se constituam para além da lógica do capital. (2014, p. 462)

(...) nossa perspectiva é pensar de que maneira a criança pode ela própria interrogar sua infância, de que maneira a criança pode infletir, interrogar, subtrair e resistir à ideia de infância, quando ela se apresenta como um dispositivo fabricado e, de certa maneira, garantidor de um funcionamento da sociedade. (2014, p. 464)

(...) Há que se restabelecer as distribuições de posição, de lugar e de poder entre adultos e crianças, de maneira a emancipar e dar autonomia às crianças (...). É pensar as políticas para a criança a partir do conceito positivo de infância. (2014, p. 467)

Impõe-se, ainda, a necessidade de um olhar decolonial sobre o problema devido ao fato de a articulação do tráfico de pessoas nas diferentes regiões do Brasil ocorrer de maneira muito peculiar. A exemplo, cita-se trecho de romance constante da literatura, a qual narra acerca do tráfico de crianças para fins de exploração sexual na Amazônia paraense:

Esse tráfico está no caminho de Caiena e Suriname. E antes, ali no Marajó. Essas cidades tipo Soure, Breves, Portel, Melgaço, ali perto do estreito (...) tem muita coisa disso. A gente não pode agir porque falta verba (...). A delegacia fluvial não tem pessoal suficiente nem lancha pra fiscalizar. (...) Mas tem outra vertente, que envia para cidades como Goiânia, Porto Alegre e também para a Espanha. (AUGUSTO, 2019, p. 36-37)

Assim, visando a análise acerca da possibilidade de se tratar da proteção integral de crianças e adolescentes vítimas de tráfico de pessoas, no contexto da política nacional de enfrentamento ao tráfico de pessoas, desde seu cerne histórico, social e legislativo, bem como da interferência de questões de deslocamentos humanos historicamente relevantes, propõe-se um diálogo interdisciplinar entre os direitos humanos e os direito das crianças e adolescentes para se entender como a doutrina da proteção integral opera em seu objetivo de resguardar os direitos desta parcela da população.

Para tanto, neste trabalho são apresentadas breves considerações sobre as ocorrências de tráfico de crianças e adolescentes no Brasil, incluindo a sua definição jurídica. Em seguida, é feita a análise da política nacional e do III Plano Nacional de Enfrentamento do Tráfico de Pessoas para, ao final, ser analisado à luz da Doutrina da Proteção Integral da criança e do adolescente como possibilidade de enfrentamento do problema sob análise.

\section{TRÁFICO DE CRIANÇAS NO BRASIL: BREVES CONSIDERAÇÕES ACERCA DE UM FENÔMENO GLOBAL}

O tráfico de pessoas, seja ele para para fins de exploração sexual, trabalho forçado, tráfico de órgãos, dentre outros, é uma realidade que se afirma em escala global (LEAL e LEAL, 2005; UNODC, 2018).

É preciso observar a questão do tráfico de pessoas dentro do quadro maior das migrações humanas, em que é válido notar que a globalização, em um contexto pós-moderno, é fator que contribui para a migração (regional e internacional), bem como para a mobilidade 
interna de pessoas que buscam supostas melhores condições de vida (BAUMAN, 1999), dentro da lógica capitalista em que se inserem.

Assim, o tráfico de seres humanos para os diversos fins que se instaura está diretamente ligado a tal processo, uma vez que a lógica do mercado se expressa por meio das forças globais, bem como das consequências sociais que acarreta (HAZEU, 2004), sendo tal crime um exemplo vivo disso. É nesse contexto que mercados globalizados propagam a noção de consumo como forma de inserção social, movimento que, de tão perverso, não poupa nem mesmo corpos. (PAMPONET SÁ e SMITH, 2017)

Em que pese envolver seres humanos em sua mais ampla diversidade, tal problema atinge, também, de maneira cruel, a infância e juventude, criando verdadeiras redes de exploração de crianças e adolescentes em contexto de vulnerabilidade social, configurando uma exploração que envolve componentes culturais e econômicos. (FALEIROS, 2004)

Assim, dentre as vítimas de tráfico, encontram-se as crianças, as quais são, em que pese a construção legal da doutrina da proteção integral mais à frente explanada, pessoas, por vezes, invisibilizadas pela sociedade, realidade que constitui outro fator que dificulta o combate de tal prática criminosa.

Tal quadro é agravado, ainda, devido ao fato de que, apesar da alta taxa de população jovem no Brasil, a ausência de políticas públicas voltadas para essas pessoas torna extremamente árdua a tarefa de garantir seus direitos (CARVALHO et al, 2008).

Ademais, as políticas públicas existentes para prevenir e reprimir o tráfico de pessoas parecem, ainda hoje, se voltar com maior vigor para uma modalidade específica do referido crime, qual seja, aquele praticado com fins de exploração sexual, gerando uma necessidade atual de se "incluir, no mesmo propósito e com a mesma dose de preocupação tutelar, o combate ao tráfico de crianças enviadas para o exterior ao arrepio das normas legais de adoção" (BARROS, 2010, p.37).

Atualmente, o tráfico de pessoas é definido pela legislação brasileira nos termos da lei 13.344 de 2016, que acrescentou o artigo 149-A no Código Penal, conforme adiante se lê:

Art. 149-A. Agenciar, aliciar, recrutar, transportar, transferir, comprar, alojar ou acolher pessoa, mediante grave ameaça, violência, coação, fraude ou abuso, com a finalidade de:

I - remover-lhe órgãos, tecidos ou partes do corpo;

II - submetê-la a trabalho em condições análogas à de escravo;

III - submetê-la a qualquer tipo de servidão;

IV - adoção ilegal; ou

V - exploração sexual.

Pena - reclusão, de 4 (quatro) a 8 (oito) anos, e multa. 
$\S 1^{\stackrel{o}{-}}$ A pena é aumentada de um terço até a metade se:

I - o crime for cometido por funcionário público no exercício de suas funções ou a pretexto de exercê-las;

II - o crime for cometido contra criança, adolescente ou pessoa idosa ou com deficiência;

III - o agente se prevalecer de relações de parentesco, domésticas, de coabitação, de hospitalidade, de dependência econômica, de autoridade ou de superioridade hierárquica inerente ao exercício de emprego, cargo ou função; ou

IV - a vítima do tráfico de pessoas for retirada do território nacional.

$\S 2{ }^{\circ}$ A pena é reduzida de um a dois terços se o agente for primário e não integrar organização criminosa.

Assim, o crime é complexo, caracterizado por ações (agenciar, aliciar, recrutar, transportar, transferir, comprar, alojar ou acolher pessoa), meios (mediante grave ameaça, violência, coação, fraude ou abuso) e fins (remoção de órgãos, trabalho em condições análogas à de escravo, servidão, adoção ilegal ou exploração sexual).

A legislação internacional sobre a matéria também define o tráfico de pessoas, nos termos do Protocolo Adicional à Convenção das Nações Unidas contra o Crime Organizado Transnacional Relativo à Prevenção, Repressão e Punição do Tráfico de Pessoas, em Especial Mulheres e Crianças (Protocolo de Palermo), promulgado pelo Decreto 5.017, de 12 de março de 2004, o que, na forma do seu art. 3, "a”, faz nos seguintes termos:

\begin{abstract}
A expressão "tráfico de pessoas" significa o recrutamento, o transporte, a transferência, o alojamento ou o acolhimento de pessoas, recorrendo à ameaça ou uso da força ou a outras formas de coação, ao rapto, à fraude, ao engano, ao abuso de autoridade ou à situação de vulnerabilidade ou à entrega ou aceitação de pagamentos ou benefícios para obter o consentimento de uma pessoa que tenha autoridade sobre outra para fins de exploração. A exploração incluirá, no mínimo, a exploração da prostituição de outrem ou outras formas de exploração sexual, o trabalho ou serviços forçados, escravatura ou práticas similares à escravatura, a servidão ou a remoção de órgãos;
\end{abstract}

Na definição acima, também resta evidente que a caracterização do crime de tráfico de pessoas depende da observação concertada entre ações, meios e fins.

Quanto ao caso específico do tráfico de crianças, este constitui prática cuja atenção dispensada pelas pesquisas na área do direito ainda não corresponde de forma satisfatória à sua relevância e atualidade, sendo o enfrentamento do tema, após o advento da Lei 13.344/2016, ainda tímido, gerando uma necessidade de o olhar jurídico se voltar, também, de forma mais adequada para questões envolvendo tal fato.

A discussão permite questionar práticas que "sustentam relações de poder sobre os corpos de crianças ancoradas em uma lógica desenvolvimentista" (LEMOS e MEDEIROS, 2010), como pode vir a ser o exemplo do tráfico de crianças ora abordado.

Um documento importante de ser analisado nesse contexto é o Relatório Nacional sobre o Tráfico de Pessoas: dados 2014 a 2016, da Secretaria Nacional de Justiça e Cidadania do 
Ministério da Justiça e Segurança Pública, publicado em 2017. Tal Relatório se presta a produzir estatísticas e análises acerca do tráfico internacional e interno de pessoas no Brasil, em uma tentativa de sistematizar os dados existentes sobre o citado crime entre 2014 e 2016, a partir da análise de dados secundários disponibilizados por diversas instituições que fazem parte da rede de atendimento às vítimas de tráfico de pessoas, tais como o Ministério da Saúde e o Ministério das Relações Exteriores.

O relatório aponta, ainda, considerações acerca das estatísticas do Poder Judiciário, sistema penitenciário, Polícias, Divisão de Assistência Consular do Ministério das Relações Exteriores, Secretaria de Inspeção do Trabalho do Ministério do Trabalho, Secretaria Nacional de Assistência Social do Ministério do Desenvolvimento Social, Sistema de Informação de Agravos de Notificação e Sistema de Vigilância de Violências e Acidentes do Ministério da Saúde, mecanismos de denúncia (Ligue 180 da Secretaria Nacional de Políticas para Mulheres e Disque 100 da Secretaria de Direitos Humanos) e Defensoria Pública da União.

Após as referidas considerações gerais, em um primeiro momento, é importante fazer uma ressalva trazida no próprio documento no sentido de que existe uma séria deficiência nos dados coletados. Isso se deve, segundo o relatório, ao fato de o tráfico de pessoas ser um dos crimes subnotificados, ou seja:

\section{[...] cujo índice de denúncias ao sistema de segurança pública ou a outros integrantes da rede de enfrentamento é baixo, por razões tais como o receio da vítima de ser discriminada ou incriminada, a vergonha, o desconhecimento de sua condição de vítima, a falta de informação sobre os mecanismos de denúncia e o medo de represálias por parte do agressor. (MJSP, 2017, p.10)}

Ademais, aduz o relatório que o crime de tráfico de pessoas é de difícil identificação, por ocorrer, em regra, de forma dissimulada. Some-se a isso a falta de preparo técnico dos profissionais que atendem vítimas do tráfico, chegando a um desconhecimento do referido crime ao ponto de, muitas vezes, nem mesmo as identificar como vítimas.

Nesse sentido, válido destacar que as limitações do referido documento se devem a diversos fatores, listados nele próprio, tais como: o fato de, como dito, a validade e qualidade dos dados quantitativos sobre o tráfico de pessoas no Brasil ser altamente questionável, a inexistência de sistema de informações capazes de registrar dados de enfrentamento ao tráfico de pessoas adequadamente, a forma de apresentação de dados inadequada realizada por algumas instituições, a alta margem de erro que persiste também devido a dados registrados como "não informados" no que diz respeito a diversas variáveis para explicar o fenômeno, a ausência de periodicidade no levantamento das informações e a inconstância dos dados. 
Tal situação gera graves problemas, já que, segundo o documento citado, "uma das principais ferramentas para a implementação de uma política pública é a coleta de dados e a produção de estatísticas" (MJSP, 2017, p.10). Portanto, a partir do momento em que estas são falhas, o aperfeiçoamento de políticas públicas voltadas ao enfrentamento do tráfico de pessoas resta consideravelmente prejudicado.

O Relatório informa, ainda, que, em que pese os esforços dos sistemas de segurança pública e da justiça criminal, nas instâncias estaduais e federais, ainda se trata de iniciativas desarticuladas, reforçando a necessidade de os olhares se voltarem de forma conjunta à repressão dessa prática criminosa. E acrescenta outro ponto de extrema importância, que reflete mais uma dificuldade do sistema:

[...] a constante confusão entre tráfico de pessoas, contrabando de migrantes e imigração irregular, além da confusão entre o que seria trabalho escravo, servidão, exploração sexual ou exercício da prostituição, faz com que o fenômeno fique ainda mais desconhecido. Por vezes, vítimas de tráfico de pessoas para fins de exploração sexual são identificadas como imigrantes ilegais que estão exercendo a prostituição. Isso se agrava no tráfico interno devido a ausência de fronteiras e de instâncias de controle à liberdade de locomoção, permitindo que recrutadores, aliciadores e traficantes transitem com suas vítimas pelo território nacional com uma certa facilidade. (MJSP, 2017, p.1011)

Em que pese o relatório, por vezes, utilizar termos como "imigrantes ilegais" ou “imigrantes irregulares", entende-se que a escolha das expressões se dá de forma errônea. Isso ocorre pela carga pejorativa que tais adjetivos adquirem quando relacionados a pessoas que se deslocam de um país para outro.

O que é irregular, em verdade, não é a pessoa do migrante em si, enquanto ser vivente, mas sim sua situação jurídica conforme considerada pelas leis e critérios da política migratória do país de destino, seja ela qual for. Entendimento diverso pode ser perigoso pela forte carga discriminatória que imigrantes já sofrem em diversos países, podendo chegar ao extremo, como em alguns casos, de tal interpretação ser utilizada para justificar intervenções arbitrárias nas vidas dessas pessoas, configurando verdadeiro fenômeno biopolítico da atualidade.

Feita a consideração, retoma-se a discussão da conceituação do tráfico de pessoas, acima destacada, para lembrar a que foi adotada pelo Protocolo de Palermo e pela Lei 13.344 no Brasil, qual seja, praticar qualquer das citadas condutas do tipo penal, aplicando um ou vários de seus meios para atingir qualquer dos fins (meramente exemplificativos) do Art. 149-A do Código Penal.

Já o contrabando de migrantes, conforme definição do Protocolo Adicional à Convenção das Nações Unidas contra o Crime Organizado Transnacional, relativo ao Combate ao Tráfico de 
Migrantes por Via Terrestre, Marítima e Aérea, incorporado nacionalmente via Decreto 5.016, de 12 de março de 2004, implica a obtenção de vantagem econômica ou material com a entrada de pessoas no país de destino e se esgota quando tal fato ocorre. Essas pessoas consentem com tal prática, pois vislumbram nela uma oportunidade de atingir seu objetivo de migrar, o que é facilitado pelos contrabandistas que prometem ajudar na sua travessia e às vezes até mesmo na obtenção de documentação necessária para permanecer no país, etc.

Nesse ponto, cabe esclarecer brevemente o que significa cada uma das finalidades exemplificativas do tráfico de pessoas trazidas pela Lei 13.344/2016. Remoção de órgãos, tecidos ou partes do corpo diz respeito ao comércio ilegal de órgãos humanos, sejam eles retirados de pessoas vivas ou mortas, não importando, para a configuração do crime, o consentimento da vítima caso haja algum pagamento pela parte do corpo comercializada, já que, no Brasil, tal prática também é proibida, sendo admitida somente a doação de órgãos, nos termos da Lei 9.434, de 04 de fevereiro de 1997.

A submissão da vítima ao trabalho em condições análogas à de escravo consiste em explorar a força de trabalho de outrem como se a pessoa fosse sua propriedade, o que implica o cerceamento de direitos, sobretudo da liberdade, no sentido de que não há voluntariedade na prestação do trabalho, nem tempo determinado para sua execução. (SMITH, 2017)

A servidão, por sua vez, se dá quando uma pessoa é mantida "presa" a outra por motivos de trabalho na terra da mesma, isto é, quando alguém trabalha na terra de outrem de forma forçada, prestando serviço o qual não importa se é ou não remunerado, sendo relevante apenas o fato de que a vítima não pode se ver livre de tal condição, por qualquer motivo que seja, inclusive em razão de dívidas. (SMITH, 2017)

A adoção ilegal se refere àquela realizada à margem da lei sobre o tema, isto é, sem observância das exigências legais ou com emprego de qualquer tipo de fraude, podendo ocorrer na modalidade internacional ou dentro do próprio território brasileiro. Nesses termos, pratica o crime tanto quem subtrai criança do poder dos pais para destiná-la à adoção quanto quem promete ou entrega o filho para outrem mediante qualquer espécie de contraprestação, financeira ou não. Tal modalidade de tráfico constitui verdadeiro comércio de crianças, em regra, em situação de vulnerabilidade agravada por qualquer fator. (SMITH, 2017)

No que tange a exploração sexual, é importante diferenciá-la da exploração da prostituição. Em verdade, a primeira é gênero, enquanto que a segunda configura apenas uma de suas possíveis espécies. A prostituição consiste na troca de favores sexuais de toda ordem frente 
a uma contraprestação por parte de quem a procura. Já a exploração sexual se dá quando ocorre a apropriação dos mecanismo de abuso sexual de forma a satisfazer interesse pessoal, em regra, auferindo lucro sobre tal prática. (SMITH, 2017)

De toda forma, o que importa frisar é o fato de que o desconhecimento acerca de todos esses elementos que envolvem o tráfico de pessoas, somado ao despreparo dos atores dos sistemas de justiça e segurança pública na identificação do crime e atendimento às vítimas, bem como a ausência de políticas públicas articuladas ao enfrentamento do referido crime, refletem na deficiência das estatísticas criminais que não descortinam de forma efetiva e adequada o fenômeno do tráfico humano, tornando sua dimensão ainda consideravelmente invisibilizada.

Esclarecidos tais pontos, retoma-se a análise do Relatório do Ministério da Justiça e Segurança Pública. O referido documento tem como um de seus objetivos tentar traçar um perfil da vítima do tráfico de pessoas, o que para os fins deste trabalho é relavante especificamente do ponto de vista da faixa-etária. Antes, porém, cabe salientar outra dificuldade descrita no Relatório:

Uma das primeiras inquietações no que diz respeito ao tráfico de pessoas é o perfil da vítima, principalmente para a elaboração de políticas de prevenção. Se fossemos contar somente com as estatísticas criminais, não saberíamos nada sobre o perfil das vítimas. Isto porque quase nenhuma das polícias levante as características das vítimas quando do registro da ocorrência, nem sequer o gênero. [...] Portanto, para se descrever o perfil da vítima há que se recorrer necessariamente às outras fontes, tais como os dados levantados pelas instituições consideradas como de assistência às vítimas. (MJSP, 2017, p.33)

No que diz respeito à idade das vítimas do crime de tráfico de pessoas, o Relatório realiza tal corte metodológico a partir da utilização de dados fornecidos pelo Disque 100 da Secretaria de Direitos Humanos, bem como do Ministério da Saúde, por considerar que os dados do referido órgão são uns dos poucos que revelam a idade das vítimas de maneira confiável.

Assim, a fim de traçar o perfil da vítima de tráfico de pessoas, no que tange à idade desta, o relatório apontou que, segundo dados do Ministério da Saúde, do total de 408 casos registrados no período compreendido entre os anos de 2014 e 2016, 57 dizem respeito a pessoas com idade entre 0 e 9 anos e 104 são referentes àquelas com idade entre 10 a 19 anos. Sobre esse aspecto, descreve o referido documento:

A faixa etária de 10 a 19 anos consiste em $20 \%$ das vítimas. Isto já havia sido apontado pelo Relatório de 2005-2011 (Secretaria Nacional de Justiça \& Escritório das Nações Unidas contra Drogas e Crime, 2013), reforçando a constatação do Relatório Global, segundo o qual os/as adolescentes somam de $15 \%$ a $20 \%$ das vítimas mundialmente (UNODC, 2012). (MJSP, 2017, p.36)

Significa dizer que, em média, $39 \%$ das pessoas vítimas de tráfico de pessoas, nos três 
anos de levantamento realizado, são crianças ou adolescentes.

Igualmente, conforme dados da Secretaria de Direitos Humanos, os números referentes ao tráfico de crianças e adolescentes são preocupantes. Segundo a Secretaria, no período entre os anos de 2014 a 2016, de um total de 413 casos registrados, 31 registros diziam respeito a nascituros/recém-nascidos, 70 casos relacionavam-se a crianças de 0 a 3 anos, 63 informes reportavam-se a crianças de 04 a 11 anos e 83 casos a adolescentes de 12 a 17 anos.

Dessa forma, segundo tais dados, quase $60 \%$ do total de casos registrados no referido período foram referentes a criança e adolescentes. Nesse ponto, o relatório apresenta algumas considerações:

No entanto, da mesma forma que na interpretação dos dados da SPM, estes devem ser flexibilizados, pois: 1. O Disque 100 foi criado, a princípio, com o objetivo de receber denúncias de violações contra crianças e adolescentes, revelando, obviamente, um maior número de vítimas entre 0 e 17 anos; 2 . O número de pessoas que não informaram a idade no período levantado contabiliza $35 \%$. Ou seja, a margem de erro também é muito grande, assim como nos dados da SPM. (MJSP, 2017, p.37)

Cabe registrar uma importante reflexão. Apesar dos números acima serem consideráveis, deve-se atentar ao fato da subnotificação existente e apontada no próprio relatório como possibilidade diante da dificuldade de construção de bancos de dados no Brasil.

Vale, ainda, apontar um outro fator que impede o conhecimento adequado do tráfico de crianças no país: a ausência de dados qualitativos que permita saber em quais fluxos os criminosos operam, mediante quais ardis traficam crianças e para quais finalidades.

Frente a tais problemas, é necessário visualizar o tráfico de crianças não somente no âmbito criminal, mas também sob diversos outros aspectos que o envolvem, como a influência da globalização, processos migratórios e exclusão social. Ainda, é necessário problematizar a crise da proteção à criança e ao adolescente, diante da necessidade de enfrentamento do tema principal, em um contexto de indiferença social, lançando mão do debate acerca de como (e se) a doutrina da proteção integral resiste a esse quadro.

Antes, porém, é imperioso que se explane acerca da política brasileira de enfrentamento ao tráfico de pessoas, o que se faz a seguir.

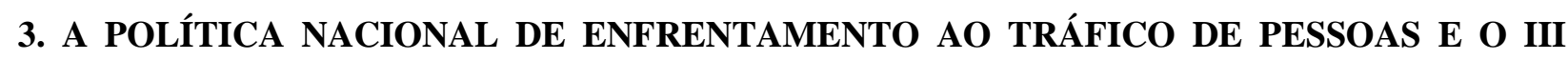 PLANO NACIONAL}

A política nacional de enfrentamento ao tráfico de pessoas foi instaurada no Brasil mediante a publicação do Decreto 5.948, de 26 de outubro de 2006, com a "finalidade de estabelecer princípios, diretrizes e ações de prevenção e repressão ao tráfico de pessoas e de atendimento às vítimas", conforme dispostições anexos. (art. $1^{\circ}$ ). 
No anexo, é apresentado o conceito de tráfico de pessoas adotado pela política nacional, sendo este o mesmo do Protocolo de Palermo, bem como as definições de criança, rapto, escravatura ou práticas similares à escravatura, já abordadas acima.

Mas torna-se importante registrar os conceitos de tráfico interno (quando realizado dentro de um mesmo estado-membro da federação ou de um estado-memebro para outro, sem sair das fronteiras nacionais) e tráfico internacional (quando ocorre com transposição das fronteiras nacionais). (Art. $2^{\circ}, \S 5^{\circ}$ e $\S 6^{\circ}$ )

Também são apresentados os princípios, diretrizes e ações que deveriam ser adotadas pelos diferentes órgãos públicos para a atuação concertada no enfrentamento ao tráfico de pessoas.

Assim, no art. $3^{\circ}$ são apontados como princípios da política nacional os seguintes:

I - respeito à dignidade da pessoa humana;

II - não-discriminação por motivo de gênero, orientação sexual, origem étnica ou social, procedência, nacionalidade, atuação profissional, raça, religião, faixa etária, situação migratória ou outro status;

III - proteção e assistência integral às vítimas diretas e indiretas, independentemente de nacionalidade e de colaboração em processos judiciais;

IV - promoção e garantia da cidadania e dos direitos humanos;

$\mathrm{V}$ - respeito a tratados e convenções internacionais de direitos humanos;

VI - universalidade, indivisibilidade e interdependência dos direitos humanos; e

VII - transversalidade das dimensões de gênero, orientação sexual, origem étnica ou social, procedência, raça e faixa etária nas políticas públicas.

Parágrafo único. A Política Nacional de Enfrentamento ao Tráfico de Pessoas observará os princípios da proteção integral da criança e do adolescente.

Destacam-se algumas diretrizes gerais da política nacional de enfrentamento ao tráfico de pessoas, voltadas para a construção de uma atução articulada entre os diferentes entes federativos, o fomento à cooperação internacional, a articulação com entidades nãogovernamentais, a estruturação de uma rede para enfrentamento do crime, o fortalecimento da atuação nas fronteiras nacionais, o atendimento à vítima, o incentivo à pesquisa e capacitação de profissionais, a harmonização legislativa sobre o tema, o incentivo à participação da sociedade civil e a ampla divulgação social sobre o tema. (art. $4^{\circ}$ )

São apontadas as diretrizes específicas de prevenção ao tráfico de pessoas, das quais se destacam a implementação de políticas públicas intersetoriais integradas e a realização de campanhas de informação e orientação. (art. $5^{\circ}$ )

No que tange às diretrizes para a repressão ao crime, destacam-se a busca pela responsabilização dos autores por meio da cooperação entre os órgãos policiais nacionais e internacionais, a cooperação jurídica internacional e a integração com as politicas de repressão aos crimes correlatos. $\left(\right.$ Art. $\left.6^{\circ}\right)$ 
Quanto à atenção às vítimas, destacam-se as diretrizes voladas para o amplo atendimento de necessidades relacionadas à assistência jurídica, social e de saúde, à assistência consular, ao acolhimento e abrigo provisório, à reinserção social e familiar, à atenção às necessidade específicas relacionadas às questões de gênero, orientação sexual, origem étnica ou social, procedência, nacionalidade, raça, religião, faixa etária, situação migratória, atuação profissional ou outro status, bem como a proteção da intimidade e da identidade das vítimas. (Art. $\left.7^{\circ}\right)$

A política nacional também apresenta as ações específicas a serem adotadas para o enfrentamento ao tráfico de pessoas, definindo ações em diversas áreas, conforme abaixo se apresenta de forma resumida: (art. $8^{\circ}$ )

- Justiça e Segurança Pública (desde o atendimento humanizado à vítima, passando pela articulação dos diferentes órgãos, qualificação de profissionais sobre o crime, organização e integração dos bancos de dados até a articualação com os casos de desaparecimentos);

- Relações Exteriores (especialmente para ratificação de documentos internacional e a cooperação internacional)

- Educação (notadamente para desenvolvimento de ações de pesquisa, formação e unidades curriculares)

- Saúde (para garantir atenção integral às vítimas do tráfico de pessoas, estabelecer as notificações compulsórias, elaboração de protocolos de padronização do atendimento às vítimas e capacitação dos profissionais)

- Assistência Social (assistência integral às vítimas, com o seu acolhimento; capacitação dos agentes da assistência social; implementação de programas e projetos de atendimento específicos às vítimas de tráfico de pessoas)

- Promoção da igualdade racial (especialmente com estudos e pesquisas sobre o perfil das vítimas de tráfico de pessoas)

- Trabalho (orientação dos empregadores sobre recrutamento de trabalhadores e os aspectos relacionados com os deslocamentos deles, fiscalização do trabalho, reinserção das vítimas no mercado de trabalho)

- Desenvolvimento Agrário (diminuir a vulnerabilidade do trabalhador e prevenir o recrutamento mediante políticas específicas na área de desenvolvimento rural, excluir das licitações e crédito rural todas as pessoas físicas ou jurídicas que explorem o trabalho forçado ou em condição análoga a de escravo, promover a reinclusão de trabalhadores libertados) 
- Direitos Humanos (especial atenção na proteção de vítimas, réus colaboradores e testemunhas do crime; criaçãodo serviço de disque-denúncia nacional; proteção aos agentes que atuem no combate ao crime; inclusão do tema nas capacitações dos Conselhos de Direitos da Criança e do Adolescente e Conselhos Tutelares; articular ações conjuntas de enfrentamento ao tráfico de crianças e adolescentes em regiões de fronteira; prevenção ao trabalho escravo)

- Proteção e Promoção dos Direitos da Mulher (capacitação dos agentes da rede de atendimento à mulher em situação de violência para o atendimento à mulher traficada; incentivo ao estabelecimento de serviços e metodologias de atendimento à mulher vítima do tráfico de pessoas; fomento ao debate sobre as causas favorecedoras do tráfico de pessoas e relativas à discriminação de gênero)

Há, também, ações previstas nas áreas do turismo e da cultura. O Decreto instituiu, ainda, o Grupo de Trabalho Interministerial, composto por diversas Secretarias e Ministérios, que podiam convidar entidades não governamentais a participar dos trabalhos, competinto a este grupo, em 90 dias, a construção do plano nacional de enfrentamento ao tráfico de pessoas.

Assim, em 2008 foi aprovado o I Plano Nacional de Enfrentamento ao tráfico de pessoas, por meio do Decreto 6.347, de 08 de janeiro, o qual deveria ser executado pelo prazo de 02 anos, ou seja, até 2010. Porém, apenas em 2013 foi aprovado o II Plano Nacional, o qual teve vigência até 2016.

O III Plano Nacional de Enfrentamento ao Tráfico de pessoas somente foi aprovado em 2018, por meio da promulgação do Decreto 9.440, de 03 de julho, o qual será executado no prazo de quatro anos (Art. $5^{\circ}$ ), ou seja, até o ano de 2022.

A estruturação do III Plano Nacional apresenta-se com a disposição inicial dos seus objetivos, os quais estão dispostos no Art. $2^{\circ}$ e são relacionados à melhoria da atuação dos entes federativos na prevenção e repressão ao tráfico de pessoas, tanto na responsabilização dos autores quanto na atenção às vítimas, bem como dirige-se ao fortalecimento da coorperação entre os órgãos públicos, entidades da sociedade civil e organismos internacionais, redução das vulnerabilizações sofridas por pessoas em relação ao tráfico de pessoas, considerando as especificidades de cada grupo, a capacitação de profissionais para atuação no tema e a podução e disseminação de informações com a sensibilização da sociedade.

Também são apresentados seis eixos temáticos nos quais se organiza o III Plano 
nacional: a gestão da política e a gestão da informação, capacitação, responsabilização, assistência às vítimas e prevenção e conscientização pública. (Art. $3^{\circ}$ ) $\mathrm{O}$ anexo do Decreto apresenta as metas relacionadas a cada eixo temático.

Assim, para os fins deste trabalho, abaixo, apresenta-se as metas relativas ao tráfico de crianças, para que seja possível visualizar se há efetivamente, na construção do III Plano, essa preocupação. Para tanto, realizou-se a busca das palavras "criança e adolescente" no documento, o que possibilitou a identificação de duas ocorrências.

O primeiro registro específico dos termos "crianças e adolescentes", no III Plano Nacional de Enfrentamento ao Tráfico de Pessoas, aparece logo no estabelecimento das metas do Eixo 1, voltado para a gestão da política, em que a meta 1.2 dispõe:

Revisar programas e serviços do Governo federal que se referem direta ou indiretamente ao enfrentamento ao tráfico de pessoas, com explicitação dos enfoques de gênero e de orientação sexual e da garantia de direitos de crianças e adolescentes.

Observa-se que uma preocupação da atual organização nacional para atuação dos órgãos públicos e entidades da sociedade civil na questão, com enfoque específico no público infanto-juvenil, está na realização de levantamento acerca dos programas e serviços do governo federal existentes na área do tráfico de pessoas com enfoque específico na garantia de direitos de crianças e adolescentes.

O segundo registro específico do III Plano Nacional diz respeito ao eixo 5, sobre assistência às vítimas, em que a meta 5.3 determina:

Fortalecer redes locais de acolhimento a vítimas de tráfico de pessoas nos Municípios, para adoção de práticas de respeito às perspectivas de gênero e orientação sexual, às crianças e aos adolescentes, com o desenvolvimento de uma experiência local, com vistas à construção de um modelo de integração de políticas públicas.

Portanto, averigua-se a preocupação forte com a atuação no acolhimento de vítimas de tráfico de pessoas nos Municípios, pelo que passa a ser uma meta o fortalecimento das redes locais, especialmente aquelas relativas ao acolhimento de crianças e adolescentes, objeivando a construção de um modelo de integração de políticas públicas.

Utilizando-se como termo de pesquisa apenas a palavra "criança", nenhuma meta foi identificada no III Plano Nacional. Porém, ao se pesquisar apenas com o termo "adolescentes" foi localizada, no eixo 6 , relativo à prevenção e conscientização pública, a meta 6.1, a qual dispõe sobre "realizar estudos sobre a condição de atletas adolescentes e sua relação com o tráfico de pessoas”.

Fora esses registros, não foram identificados outras metas específicas ao público infanto-juvenil nos demais eixos (gestão da informação, capacitação e responsabilização). 
Assim, abaixo, analisa-se em que medida a doutrina da proteção integral serve como instrumento de enfrentamento ao tráfico de crianças.

\section{A DOUTRINA DA PROTEÇÃO INTEGRAL: POSSIBILIDADES DE ENFRENTAMENTO DO PROBLEMA}

A doutrina da proteção integral trata da garantia de direitos fundamentais de toda ordem, reconhecidos no âmbito internacional, a crianças e adolescentes enquanto sujeitos que os detém integralmente, gerando uma necessidade atual de se analisar como e se ocorre tal proteção, especificamente quando se trata de grupo vulnerável como é o caso de crianças traficadas.

Assim, visando à efetivação dos Direitos Humanos dessa parcela da população, bem como à busca por soluções para o problema posto, é indispensável a análise crítica da proteção integral enquanto possibilidade de enfrentamento do tema.

Ressalte-se que a referida prática criminosa influencia, como já exposto, na migração de crianças e adolescentes do Brasil para outras regiões do mundo, configurando espécie de deslocamento humano que ainda muito carece de estudos aprofundados, sobretudo do ponto de vista jurídico. Daí, também, surge a necessidade de se questionar acerca de meios que promovam a inclusão social de tais pessoas, visto que, devido à (re)vitimização que sofrem, sua reinserção no meio social e familiar ocorre de maneira peculiar.

Assim, entende-se necessário problematizar o tema principal sob a ótica da doutrina da proteção integral, a partir de uma reflexão crítica e interdisciplinar em relação ao objeto de estudo, ante a construção social da ideia de infância formulada em uma ordem adultocêntrica (RIOS, 2015), a fim de se verificar como seus postulados são interpretados e aplicados em nosso ordenamento jurídico, bem como sua legitimidade para além da mera legalidade, visando analisar se há como se falar de proteção integral de crianças vítimas de tráfico de pessoas no contexto da política nacional de enfrentamento ao tráfico de pessoas.

Tudo isso porque a doutrina da proteção integral dos direitos da infância e adolescência diz respeito a uma série de instrumentos jurídicos internacionais, com princípios incorporados pelo ordenamento jurídico pátrio, que, ao proteger prioritariamente a criança e o adolescente, elevou-os, em tese, ao patamar de sujeitos de direito, rompendo com a doutrina da situação irregular anteriormente aceita.

Assim, surge enquanto modelo da escola de reação social, rompendo com a escola etiológica, de forma que as condições pessoais da criança deixam de ser motivo bastante para intervenção estatal, passando a ser exigido, para tanto, a existência de situação concreta a ser 
tutelada pelo direito (SARAIVA, 2010). Dessa forma, superou-se, teoricamente, o paradigma da incapacidade e adotou-se o paradigma da peculiar condição da pessoa em desenvolvimento, resultando em um modelo de proteção integral da criança e do adolescente.

Nesse contexto, o sistema de atendimento a crianças e adolescentes foi totalmente reestruturado, passando a constituir um sistema de garantia de direitos, que visa à proteção máxima daqueles, dentro dos ditames legais. A solução para os problemas da infância e adolescência ganha nova roupagem, inclusive com participação ativa da própria sociedade no que tange as políticas voltadas a esse público.

Importante destacar que o novo paradigma trazido pela proteção integral, consolidada nas novas regras estatutárias, vai além de garantias meramente processuais, incluindo em nosso ordenamento jurídico a necessidade de políticas sociais básicas (saúde, educação, cultura, esporte e lazer), políticas assistenciais (abrigo, transporte, capacitação ao trabalho, etc) e políticas de proteção especial (atendimento especializados a crianças e adolescentes em situação de risco, aplicação de medidas protetivas e socioeducativas).

O discurso por trás desse novo sistema é o de permitir que a proteção integral, por não apenas definir direitos, como também mecanismos de garantia destes, não seja mera retórica, a partir da integração de órgãos e agentes na busca pelo objetivo precípuo de atendimento às necessidades de crianças e adolescentes enquanto sujeitos de direitos.

No plano internacional, diversos documentos permitiram que a doutrina da proteção integral ganhasse força, tornando-se parâmetro para a resolução de questões envolvendo crianças e adolescentes. Importante citar os principais: Declaração de Genebra (1924), Declaração Universal dos Direitos Humanos (1948), Declaração dos Direitos da Criança (1959), Pacto San José da Costa Rica (1969), Regras de Beijing (1985), Convenção sobre os Direitos da Criança (1989), Regras Mínimas das Nações Unidas para a Proteção dos Jovens Privados de Liberdade (1990) e Diretrizes de Riad (1990).

Tais documentos trouxeram em seu bojo determinações que demonstram que crianças e adolescentes devem ser tratados com dignidade, considerando-se, sempre, a condição peculiar da pessoa em desenvolvimento, o que permite a construção de um cenário favorável à maior proteção dessas pessoas. Trata-se do nascimento de uma nova forma de perceber a condição da infância e adolescência, garantindo às pessoas menores de 18 anos direitos fundamentais de toda ordem.

SARAIVA (1992) destaca acerca do relatório da oficina da justiça da infância e 
juventude no seminário latino-americano de direitos da criança. Tal documento realizou importantes considerações acerca da doutrina da proteção integral, demonstrando a importância de consolidá-la em nosso ordenamento.

Assim, o referido relatório concluiu que o sistema baseado na doutrina da situação irregular não era suficiente para atender às necessidades dos países latinos, já que a "justiça de menores" era tida como de pouca importância e, com isso, os direitos fundamentais da pessoa humana não eram garantidos de forma satisfatória a crianças e adolescentes, não passando tal sistema de um instrumento de controle social da pobreza, que judicializava questões sociais desnecessariamente.

A mudança paradigmática, então, foi necessária até mesmo para que princípios da Convenção Internacional fossem respeitados e incorporados pelos países signatários, com o intuito de se garantir às crianças e adolescentes uma gama de direitos antes ignorada, visando a sua inclusão social, o que passaria a ser possível graças ao implemento da ideologia de proteção integral.

Em síntese, a referida doutrina preceitua a igualdade de direitos entre todas as crianças e adolescentes, que devem ser protegidos sem qualquer forma de distinção, bem como uma integralidade desses direitos.

Em termos legais, a doutrina da proteção integral foi consagrada no Art. 227 da Constituição Federal de 1988, que, ao fazê-lo, passou a considerar que todas as crianças e adolescentes são sujeitos detentores de direitos, os quais possuem prioridade absoluta no atendimento de seus interesses, bem como determinou que a responsabilidade de garantir seus direitos fundamentais é da família, da sociedade e do Estado, os quais devem atuar em conjunto na busca desse objetivo.

Após o advento da Constituição de 1988, em 13 de julho de 1990, ocorreu a promulgação do Estatuto da Criança e do Adolescente (ECA), o qual regulamentou os princípios expressos no art. 227 daquela, de forma que tais disposições foram reproduzidas, com uma maior explanação do conceito da doutrina da proteção integral ao longo de todo o texto do referido diploma legal.

Assim, tanto o ECA quanto a Constituição Federal implantaram a proteção integral como pilar do sistema brasileiro, tornando responsabilidade de todos a garantia dos direitos fundamentais da criança e do adolescente, a serem tratados com prioridade, entendidos como pessoas em desenvolvimento e que, por isso, gozam de maior proteção jurídica (VERONESE, 2015). O ECA, então, determina, em seu primeiro livro, os direitos fundamentais das crianças e 
adolescentes e, no segundo, os mecanismos e agentes necessários para a garantia destes direitos.

O ECA reforça a ideologia da proteção integral, ainda, ao trazer nova política de atendimento, enfatizando o dever de cooperação de todos os entes federados nas políticas envolvendo crianças e adolescentes (BENTES, 2013).

Diante de todos esses direitos alcançados, ao menos em tese, pela infância e adolescência brasileiras, fato é que, ao se analisar situações como a de crianças traficadas, seja para trabalhos forçados, para adoções nacionais e/ou internacionais fraudulentas, para retirada de órgãos, para exploração sexual, dentre outras graves violações de direitos humanos dessa parcela da população, é impossível não se atentar para as falhas em sua aplicação.

Ora, se a doutrina da proteção integral é o meio de combater tais problemas, a partir do momento em que ele se afirma em escala global como prática diária, abre-se espaço para questionar até que ponto o avanço nos direitos dessas pessoas passou, verdadeiramente, da teoria à prática.

Quando se analisa a Política Nacional de Enfrentamento ao Tráfico de Pessoas e o III Plano Nacional de Enfrentamento ao Tráfico de Pessoa, mesmo conscientes das mudanças governamentais que operam diferenciação na atuação do Estado, observa-se a ausência de prioridade que é dada à questão quando se trata de crianças e adolescentes vítimas.

Por mais que os referidos documenos abordem de maneira geral a necessidade de produção de conhecimento da realidade em que se opera o tráfico de pessoas no Brasil, da melhor estruturação das políticas públicas de prevenção, da adequada atuação em rede e articulação dos diferentes órgãos dos sistemas de segurança pública, assistência, justiça, saúde e educação, quando se analisa amiúde os textos a preocupação com a criança e o adolescente é ínfima, talvez isso justifique a ausência, até os dias atuais, de dados qualificados publicados pelos órgãos responsáveis que permita à sociedade e ao próprio Estado atuar de modo eficaz na prevenção e no enfrentamento ao tráfico de pessoas, com efetiva responsabilização dos agentes criminosos e eficiente atendimento às vítimas.

\section{CONSIDERAÇÕES FINAIS}

Pelas inquietações iniciais até aqui expostas, revela-se inconteste a extrema necessidade de estudo e aprofundamento investigativo sobre o tráfico de crianças no Brasil enquanto prática que influencia e é influenciada pelos deslocamentos de crianças pelas rotas em que se opera. Isto significa, antes de tudo, uma problematização imperativa do tratamento que vem sendo dispensado a crianças e adolescentes pelo ordenamento jurídico, pautado na doutrina da proteção 
integral.

É fato que o estado atual dos conhecimentos na área ainda não dá conta de sua amplitude histórica, social e jurídica de forma satisfatória, dando espaço a maiores investigações do tema, como a que ora se propôs realizar.

Longe de fornecer uma resposta definitiva à questão abordada, buscou-se, neste trabalho, apontar provocações que possibilitem reflexões informadas sobre o tema, a fim de promover a busca por soluções jurídicas, mas também sociais, para o problema posto, o qual, apesar de extrapolar as fronteiras territoriais do país, revela-se como séria questão regional e nacional.

É imperioso que as políticas públicas de proteção integral à criança e ao adolescente sejam consideradas na política nacional de enfrentamento do tráfico de pessoas, pois é indispensável que a prevenção e a repressão ao crime, bem como a devida atenção às vítimas, leve em consideração as necessidades especiais de crianças e adolescentes enquanto pessoas em desenvolvimento.

Para tanto, torna-se indispensável a produção de dados qualificados sobre como o tráfico de crianças se opera no Brasil, em quais rotas, com quais agentes, sob quais meios e para quais finalidades, pois sem conhecer a realidade não há possibilidade de efetivo enfrentamento do problema. E sem priorizar o público infanto-juvenil na produção de dados e no estabelecimento das políicas públicas, não existe proteção integral e prioridade absoluta.

\section{REFERÊNCIAS}

ABRAMOWICZ, Anete; RODRIGUES, Tatiane C. Descolonizando as pesquisas com crianças e três obstáculos. Educ. Soc., Campinas, v. 35, n. 127, p; 461-474, abr-jun. 2014. Disponível em https://www.cedes.unicamp.br/. Acesso em 10 set. 2019.

AUGUSTO, Edyr. Pssica. São Paulo: Boitempo, 2019.

BARROS, Marco Antonio de. Tráfico de Pessoas Para Fim de Exploração Sexual e a Adoção Internacional Fraudulenta. Disponível em http://www.institutoelo.org.br/site/files/publications/e952d35650c7015da6816b8dae3041f1.pdf. Acesso em 27 set. 2018.

BAUMAN, Zygmunt. Globalização: as consequências humanas. Rio de Janeiro: Zahar, 1999. BENTES, Nadia M. Defensoria Pública: desafios institucionais para a defesa da criança e do adolescente. In: HAMOY, Ana Celina B. (org). Direitos Humanos de Crianças e Adolescentes Nos Dias de Hoje: entre o ideal e o real. $1^{\mathrm{a}}$ ed. Belém: Movimento República do Emaús, 2013.

BRASIL. Decreto $\mathbf{n}^{\circ}$ 5.016, de 12 de março de 2004. Promulga o Protocolo Adicional à Convenção das Nações Unidas contra o Crime Organizado Transnacional, relativo ao Combate ao Tráfico de Migrantes por Via Terrestre, Marítima e Aérea. Disponível em http://www.planalto.gov.br/ccivil 03/ Ato2004-2006/2004/Decreto/D5016.htm. Acesso em 20 mar. 2020.

BRASIL. Decreto no 5.017, de 12 de março de 2004. Promulga o Protocolo Adicional à Convenção das Nações Unidas contra o Crime Organizado Transnacional Relativo à Prevenção, Repressão e Punição do Tráfico de Pessoas, em Especial Mulheres e Crianças. Disponível em http://www.planalto.gov.br/ccivil_03/_Ato2004-2006/2004/Decreto/D5017.htm. Acesso em 20 mar. 
2020.

BRASIL. Decreto no 5.948, de 26 de outubro de 2006. A prova a Política Nacional de Enfrentamento ao Tráfico de Pessoas e institui Grupo de Trabalho Interministerial com o objetivo de elaborar proposta do Plano Nacional de Enfrentamento ao Tráfico de Pessoas - PNETP. Disponível em http://www.planalto.gov.br/ccivil_03/_Ato2004-2006/2006/Decreto/D5948.htm. Acesso em 25 abr. 2020.

BRASIL. Decreto $\mathbf{n}^{\mathbf{0}}$ 6.347, de 8 de janeiro de 2008. Aprova o Plano Nacional de Enfrentamento ao Tráfico de Pessoas PNETP e institui Grupo Assessor de Avaliação e Disseminação do referido Plano. Disponível em http://www.planalto.gov.br/CCIVIL 03/ Ato2007-2010/2008/Decreto/D6347.htm. Acesso em 25 abr. 2020.

BRASIL. Decreto $n^{\circ}$ 9. 440, de 03 de julho de 2018. Aprova o III Plano Nacional de Enfrentamento ao Tráfico de Pessoas. Disponível em https://www.justica.gov.br/sua-protecao/trafico-depessoas/politica-brasileira/dec-9440-18-iii-plano.pdf. Acesso em 25 abr. 2020.

BRASIL. Lei no 8.069, de 13 de julho de 1990. Dispõe sobre o Estatuto da Criança e do Adolescente e dá outras providências. Disponível em http://www.planalto.gov.br/ccivil_03/leis/18069.htm. Acesso em 20 mar. 2020.

BRASIL. Lei no 13.344, de 6 de outubro de 2016. Dispõe sobre prevenção e repressão ao tráfico interno e internacional de pessoas e sobre medidas de atenção às vítimas; altera a Lei no 6.815 , de 19 de agosto de 1980, o Decreto-Lei n ${ }^{\circ} 3.689$, de 3 de outubro de 1941 (Código de Processo Penal), e o Decreto-Lei n ${ }^{\circ}$ 2.848, de 7 de dezembro de 1940 (Código Penal); e revoga dispositivos do Decreto-Lei $\mathrm{n}^{\mathrm{o}} 2.848$, de 7 de dezembro de 1940 (Código Penal). Disponível em http://www.planalto.gov.br/ccivil_03/_ato20152018/2016/lei/113344.htm. Acesso em 20 mar. 2020.

CARVALHO, Quitéria Clarice Guimarães. et al. Violência Contra Criança e Adolescente: reflexão sobre políticas públicas. Disponível em http://www.redalyc.org/html/3240/324027962018/. Acesso em 20 ago. 2018.

COMITE SOBRE OS DIREITOS DA CRIANÇA. General Comment n. 6: on treatment of unaccompanied and separated children outside their country of origin. CRC/GC/2005/6. 2005. Disponível em https://www2.ohchr.org/english/bodies/crc/docs/GC6.pdf. Acesso em 10 out. 2018. ESCRITÓRIO DAS NAÇÕES UNIDAS PARA DROGAS E CRIME. Relatório Global sobre Tráfico de Pessoas 2018. Consultada a 13.03.2010. Em https://www.unodc.org/documents/lpobrazil//Topics_TIP/Publicacoes/TiP_PT.pdf.

FALEIROS, Eva T. Silveira. A Exploração Sexual Comercial de Crianças e Adolescentes no Mercado do Sexo. In: LIBÓRIO, Renata Maria Coimbra. SOUSA, Sônia M. Gomes (org.). A Exploração Sexual de Crianças e Adolescentes no Brasil: reflexões teóricas, relatos de pesquisas e intervenções psicossociais. São Paulo: Casa do Psicólogo, 2004.

FONSECA, Cláudia. Uma Virada Imprevista: o "fim" da adoção internacional no Brasil. DADOS - Revista de Ciências Sociais, Rio de Janeiro, v. 49, n. 1, pp. 41-66, 2006. DIsponível em: http://www.scielo.br/pdf/\%0D/dados/v49n1/a03v49n1.pdf. Acesso em 15 ago. 2018.

HAZEU, Marcel Theodor. Direitos Sexuais da Criança e do Adolescente: uma visão interdisciplinar para o enfrentamento da violência sexual contra crianças e adolescentes. Belém: Movimento República do Emaús, 2004.

JORDY, Arnaldo; MORAIS, Flávia. Relatório Final da Comissão Parlamentar de Inquérito Sobre Tráfico de Pessoas. Câmara dos Deputados: Brasília, 2014. DIsponível em http://www2 .camara.leg.br/atividade-legislativa/comissoes/comissoes- temporarias/parlamentar-deinquerito/54a-legislatura/cpi-trafico-de-pessoas-no-brasil/relatorio- final-aprovado-e-parecer-dacomissao/relatorio-final-aprovado-e-parecer-da-comissao. Acesso em 20 jul. 2018.

LEAL, Maria Lúcia; LEAL, Fátima (Org.). Tráfico de Mulheres, Crianças e Adolescentes para Fins de Exploração Sexual Comercial: um fenômeno transnacional. Lisboa: SOCIUS - Centro de Investigação em Sociologia Económica e das Organizações, 2005. Disponível em http://www.repository.utl.pt/bitstream/10400.5/2002/1/wp200504.pdf. Acesso em 29 jun. 2018.

LEMOS, Flávia Cristina Silveira; MEDEIROS, Larissa Gonçalves. A Produção da "Circulação de Crianças": entre capturas e nomadismos. Revista Estudos e Pesquisa em Psicologia, Rio de 
Janeiro, v. 11, n. 3, jul/dez 2010.

MEZMUR, Benyam D. Adoção Internacional como Medida de Último Recurso na África: promover os direitos de uma criança ao invés do direito a uma criança. SUR - Revista Internacional de Direitos Humanos, São Paulo, ano 6, n. 10, pp. 82-105, jun 2009. MINISTÉRIO DA JUSTIÇA E SEGURANÇA PÚBLICA. Relatório nacional sobre o tráfico de pessoas: dados 2014 a 2016. Disponível em: https://legado.justica.gov.br/sua-protecao/trafico-depessoas/publicacoes/relatorio-de-dados.pdf.

Acesso em 28 abr. 2020.

PAMPONET SÁ, Yasmim. SMITH, Andreza do Socorro Pantoja de Oliveira. Tráfico de Pessoas Transexuais na Adolescência para Fins de Exploração Sexual no Brasil: enfrentamentos a partir da doutrina da proteção integral. In: Seminário Internacional América Latina: Políticas e Conflitos Contemporâneos, 2., 2017, Belém. Anais [...]. Belém: UFPA, 2017. pp. 4191-4202. Disponível em: https://sialat2017.com/wp- content/uploads/2018/02/GT-08-COMPLETO.pdf. Acesso em: 19 set. 2018.

RIOS, Roger Raupp. Minorias, direitos de crianças e adolescentes: notas sobre o reconhecimento, proteção e promoção nas perspectivas do direito da sexualidade e do direito da antidiscriminação. Hendu Revista Latino-Americana de Direitos Humanos, v. 6, n. 2, pp. 16-24, 2015.

SARAIVA, João B. C. Compêndio de Direito Penal Juvenil - Adolescente e Ato Infracional. $4^{a}$ ed. rev. e atual. Porto Alegre: Livraria do Advogado, 2010. SMITH, Andreza do Socorro Pantoja de Oliveira. Tráfico de Pessoas para Exploração Sexual. Rio de Janeiro: Lumen Juris, 2017.

VERONESE, Josiane Rose P. Direito Penal Juvenil e Responsabilização Estatutária: elemento aproximativos e/ou distanciadores? - o que diz a Lei do Sinase - a inimputabilidade penal em debate. Rio de Janeiro: Lumen Juris, 2015. 